\title{
Our Patients Do Not Need Endocarditis Prophylaxis for Genitourinary Tract Procedures: Insights From the 2007 American Heart Association Guidelines
}

\author{
Eliana Castillo, MD, FRCPC, ${ }^{1,6}$ Laura A. Magee, MD, FRCPC, ${ }^{1,2,3,5,7}$ \\ Peter von Dadelszen, MBChB, DPhil, FRCSC, ${ }^{2,3,5,6}$ Deborah Money, MD, FRCSC, ${ }^{2,6,7}$ \\ Edith Blondel-Hill, MD, FRCPC, ${ }^{4,6}$ Julie van Schalkwyk, MD, FRCSC ${ }^{2,6,7}$ \\ ${ }^{1}$ Department of Medicine, University of British Columbia, Vancouver BC \\ ${ }^{2}$ Department of Obstetrics and Gynaecology, University of British Columbia, Vancouver BC \\ ${ }^{3}$ Department of Health Care and Epidemiology, University of British Columbia, Vancouver BC \\ ${ }^{4}$ Department of Pathology and Laboratory Medicine, University of British Columbia, Vancouver BC \\ ${ }^{5}$ Centre for Advanced Health Research and Evaluation, Child and Family Research Institute, University of British Columbia, Vancouver BC \\ ${ }^{6}$ Children's and Women's Health Centre of British Columbia, Vancouver BC \\ ${ }^{7}$ Women's Health Research Institute, Vancouver BC
}

\begin{abstract}
The 2007 American Heart Association guidelines for the prevention of infective endocarditis have dramatically reduced both the types of eligible procedures and the types of eligible cardiac lesions that require prophylaxis. Antibiotic prophylaxis to prevent infective endocarditis is not indicated for any patient undergoing obstetric and/or gynaecological procedures, not even for patients with underlying cardiac lesions with the highest risk of developing complications from endocarditis. This sharp departure from previously published guidelines relies on the recognition that endocarditis is more likely to develop from "randomly occurring" bacteremia (e.g., from brushing teeth) than from invasive procedures and that antibiotic prophylaxis has not been proven to be effective. A short discussion on enterococcal infections associated to obstetric and gynaecological procedures and therapeutic implications is presented.
\end{abstract}

\section{Résumé}

Les lignes directrices 2007 de la American Heart Association en ce qui a trait à la prévention de l'endocardite infectieuse ont entraîné la baisse spectaculaire tant des types d'intervention admissibles que des types de lésion cardiaque admissibles nécessitant une prophylaxie. L'antibioprophylaxie visant à prévenir l'endocardite infectieuse n'est pas indiquée pour quelque patiente devant subir une intervention obstétricale et/ou gynécologique que ce soit, pas même pour les patientes présentant des lésions

Key Words: Infective endocarditis, obstetric and gynaecological practice, antibiotic prophylaxis

Competing Interests: None declared.

Received on December 20, 2007

Accepted on March 12, 2008 cardiaques sous-jacentes les exposant au risque le plus élevé de présenter des complications attribuables à l'endocardite. Ce changement brutal, par rapport aux lignes directrices publiées précédemment, se fonde sur la reconnaissance du fait que l'endocardite est plus probablement attribuable à une bactériémie « d'apparition aléatoire » (p. ex. attribuable au fait de se brosser les dents) qu'à l'exécution d'interventions effractives et du fait que l'efficacité de l'antibioprophylaxie n'a pas été prouvée. Une brève discussion au sujet des infections entérococciques associées aux interventions obstétricales et gynécologiques, et de leurs

implications thérapeutiques est présentée

J Obstet Gynaecol Can 2008;30(9):796-799

\section{INTRODUCTION}

Tn April 2007, the AHA published a revised version of the 1 guidelines for the prevention of infective endocarditis that have been in use since the 1960s. ${ }^{1}$ These guidelines are the first to be endorsed by both the Infectious Diseases Society of America and the Pediatric Infectious Diseases Society. The revisions to the guidelines were prompted by the recognition that there is an "extremely small number" of cases of endocarditis, that endocarditis is more likely to develop from "randomly occurring" bacteremia (e.g., from brushing teeth) than from invasive procedures and that antibiotic prophylaxis has not been proven to be effective ${ }^{1,2}$ but has clear potential adverse effects. The first of these is the emergence of antibiotic resistance associated with antibiotic use, ${ }^{3}$ and the second is the possibility of a 
hypersensitivity reaction, which with use of beta-lactams occurs at the rate of $1 \%$ to $10 \% .^{4}$

In the new guidelines, the AHA has dramatically reduced both the types of eligible cardiac lesions and the types of eligible procedures that require prophylaxis. Patients eligible for endocarditis prophylaxis under the new guidelines have cardiac conditions associated with the highest risk of developing complications from endocarditis (Table). ${ }^{1}$ However, eligible procedures no longer include those involving the GU (or GI) tract, even for cardiac lesions listed in the Table. (The reader is referred to the AHA document for a discussion of eligible procedures). A fuller discussion is warranted on what pertains to obstetric and gynaecological procedures and related infections, particularly enterococcal infections.

\section{THE PATHOGENESIS OF ENDOCARDITIS}

Infective endocarditis requires both "receptive" cardiac tissue and transient bacteremia. Most commonly, abnormal heart structures cause turbulent blood flow within the heart, resulting in damaged endothelium to which bacteria may adhere and proliferate; other receptive tissues include prosthetic cardiac material or valvular vegetations. The bacteria that have particularly high adherence to receptive cardiac tissue are Viridans group Streptococci, Staphylococcus aureus, and Enterococcus species (particularly Enterococcus faecalis).

With respect to Enterococcus species, the 2007 AHA guidelines state that in patients with cardiac conditions listed in the Table who also "have an established GI or GU tract infection, or ... who receive antibiotic therapy to prevent wound or sepsis associated with a GI or GU procedure, it may be reasonable that the antibiotic regimen include an agent active against enterococci." They go on to say that "no published studies demonstrate that such therapy would prevent enterococcal infective endocarditis."

\section{PREGNANCY}

Bacteremia following obstetric procedures is short-lived and usually involves gram-negative bacilli (e.g., Escherichia coli), gram-positive bacilli (e.g., Gardnerella vaginalis), anaerobic gram-positive cocci and Streptococcus agalactiae, $e^{5,6}$ instead of VGS, Stapylococcus aureus, or Enterococcus faecalis. Reported risk factors for developing bacteremia in the obstetric

\section{ABBREVIATIONS}

$\begin{array}{ll}\text { AHA } & \text { American Heart Association } \\ \text { GI } & \text { gastrointestinal } \\ \text { GU } & \text { genitourinary } \\ \text { VGS } & \text { viridans group streptococci }\end{array}$

Patients at the highest risk of developing complications from infective endocarditis ${ }^{1}$

1. Patients with previous infective endocarditis

2. Patients with prosthetic cardiac valve

3. Cardiac transplant recipients who develop valvulopathy

4. Patients with specific congenital heart diseases:

a. A completely repaired congenital heart defect with prosthetic material or device, whether placed by surgery or by catheter interventions, during the first six months after the procedure

b. Any repaired congenital heart defect with residual defect at the site or adjacent to the site of a prosthetic patch or prosthetic device

setting include preterm delivery, chorioamnionitis, ${ }^{5}$ and septic abortion. ${ }^{7-9}$

In the latest 2003-2005 Confidential Enquiry into Maternal And Child Health report ${ }^{10}$ cardiac disease was the leading cause of maternal death ( $\mathrm{N}=81,3.83 / 100000$ maternities). Four deaths were due to infective endocarditis, at least one case of which developed antepartum, giving a maximal rate of fatal postpartum endocarditis of 0.14 per 100000 maternities. There was no information provided in the report about antibiotic prophylaxis. By comparison, the incidence of fatal anaphylaxis from beta-lactam antibiotics is comparable (0.01 to 0.40 per 100000 exposures). ${ }^{11}$

Infective endocarditis is a rare complication of pregnancy, with an estimated incidence of 1 case per 8000 to 16000 deliveries. ${ }^{12,13}$ This incidence is likely lower nowadays as the prevalence of rheumatic valvular heart disease in developing countries has decreased. ${ }^{14,15}$ Two overlapping reviews of infective endocarditis pertain to obstetric and gynaecologic practice; the first, covering the years 1940-1983, accounts for 126 cases, ${ }^{16}$ and the second, covering the years 1966-2002, accounts for 68 cases, ${ }^{17}$ in addition to 9 more cases reported between 2002 and the present. ${ }^{18-27}$ For the purposes of this commentary, 71 cases, including all postpartum or abortion-related cases were reviewed in detail. Between $55.7 \%$ and $73.5 \%$ of cases of infective endocarditis developed during pregnancy and were unrelated to any procedure. Between $14.7 \%$ and $22.2 \%$ occurred in the first six weeks after delivery, termination of pregnancy or miscarriage, and had no alternative explanation for bacteremia (e.g., intravenous drug use). The two most common etiologic agents remained VGS $(24.1 \%)$ and Staphylococcus aureus (21\%). Only four cases of postpartum enterococcal endocarditis ${ }^{16,27}$ were identified, three of these being reported prior to 1960 , and two of them occurring in the setting of home delivery with forceps. Eleven cases of enterococcal endocarditis following abortion or a dilatation and curettage procedure have been reported, mostly among 
women with rheumatic valvular heart disease, and occurring prior to $1960 .{ }^{16}$ Antibiotic prophylaxis failed to prevent endocarditis in the two cases that described its use: one case occurred in a woman with mitral and aortic prosthetic valves who underwent therapeutic abortion, ${ }^{26}$ and the second occurred in a woman with pre-existing rheumatic valvular heart disease following vaginal delivery. ${ }^{28}$ Additionally, Streptococcus agalactiae endocarditis developed in two women who received treatment with tetracycline following therapeutic abortion. ${ }^{29,30}$ These reports suggest that postpartum endocarditis is rare, and that the potential benefits of antibiotic prophylaxis (unproven ${ }^{2}$ ) would not compare favourably with the risks of anaphylaxis in users of beta-lactams (0.6 to 3.2 per 100000 exposures). ${ }^{31}$

A conservative approach, for women with the cardiac conditions listed in the Table, may be to ensure that treatment for infections potentially involving Enterococcus species include adequate antibiotic coverage against these organisms. A list of such infections includes, but is not limited to (1) serious lower urinary tract infection or upper urinary tract infection prior to microbiological diagnosis (after which time treatment can be narrowed) ${ }^{32}$; (2) fever with no identified focus, particularly if the patient is systemically ill; or (3) infections involving the biliary tract, compromise of GI tract integrity (e.g., bowel puncture during Caesarean section), or chorioamnionitis/endometritis, because these infections tend to be polymicrobial and can potentially include Enterococcus species. If women with the cardiac conditions listed are given antibiotics to prevent wound infection, it is reasonable to include an agent with enterococcal coverage. However, in the event of sepsis, any patient (including such women) requires expedited initiation of empiric antibiotic therapy, rather than prophylaxis.

\section{GYNAECOLOGY}

Termination of pregnancy and miscarriage have been discussed above. In the absence of bowel injury or opening of the vagina, gynaecological procedures are generally considered to be "clean." Bacteremia associated with a gynaecological procedure does not usually involve VGS or Staphylococcus aureus, and endocarditis prophylaxis is not required.

\section{CONCLUSION}

The 2007 AHA guidelines for the prevention of infective endocarditis do not recommend antibiotic prophylaxis for prevention of infective endocarditis in women undergoing procedures relevant to obstetric or gynaecology care providers. However, if a woman has an infection potentially involving Enterococcus species, and she has a cardiac lesion listed in the Table, it is prudent for care providers to ensure that the antibiotic regimen used for treatment of the clinical condition includes adequate enterococcal coverage (e.g., ampicillin, or in the face of either penicillin allergy or microbial resistance, vancomycin).

\section{REFERENCES}

1. Wilson W, Taubert KA, Gewitz M, Lockhart PB, Baddour LM, Levison M, et al. Prevention of infective endocarditis: guidelines from the American Heart Association: a guideline from the American Heart Association Rheumatic Fever, Endocarditis, and Kawasaki Disease Committee, Council on Cardiovascular Disease in the Young, and the Council on Clinical Cardiology, Council on Cardiovascular Surgery and Anesthesia, and the Quality of Care and Outcomes Research Interdisciplinary Working Group. Circulation 2007;116:1736-54.

2. Van der Meer JT, Van Wijk W, Thompson J, Vandenbroucke JP, Valkenburg HA, Michel MF. Efficacy of antibiotic prophylaxis for prevention of native-valve endocarditis. [see comment]. Lancet 1992;339(8786):135-9.

3. Foucault C, Brouqui P. How to fight antimicrobial resistance. FEMS Immunol Med Microbiol 2007;49(2):173-83.

4. Dukes M, Aronson J. Meyler's side effects of drugs. 14th ed. Amsterdam (NL): Elsevier Science; 2000.

5. Boggess KA, Watts DH, Hillier SL, Krohn MA, Benedetti TJ, Eschenbach DA. Bacteremia shortly after placental separation during cesarean delivery. Obstet Gynecol 1996;87(5 Pt 1):779-84.

6. De Martino SJ, Mahoudeau I, Brettes JP, Piemont Y, Monteil H, Jaulhac B. Peripartum bacteremias due to Leptotrichia amnionii and Sneathia sanguinegens, rare causes of fever during and after delivery. J Clin Microbiol 2004;42(12):5940-3.

7. Sacks PC, Tchabo JG. Incidence of bacteremia at dilation and curettage. J Reprod Med 1992;37(4):331-4.

8. Lichtenberg ES, Henning C. Conservative management of clostridial endometritis. Am J Obstet Gynecol 2004;191(1):266-70.

9. Cherpes TL, Kusne S, Hillier SL. Haemophilus influenzae septic abortion. Infect Dis Obstet Gynecol 2002;10(3):161-4.

10. Saving mothers' lives: reviewing maternal deaths to make motherhood safer-2003-2005. The seventh report on confidential enquiries into maternal deaths in the United Kingdom. In: Lewis G, ed. The confidential enquiry into maternal and child health. London (GB): CEMACH; 2007.

11. Grahame-Smith D, Aronson J. Penicillins. In: Grahame-Smith D, Aronson J, eds. Oxford textbook of clinical pharmacology and drug therapy. Oxford (GB): Oxford University Press; 2002:569-7.

12. Ward H, Hickman RC. Bacterial endocarditis in pregnancy. Aust N Z J Obstet Gynaecol 1971;11(3):189-91.

13. Cox SM, Hankins GD, Leveno KJ, Cunningham FG. Bacterial endocarditis. A serious pregnancy complication. J Reprod Med 1988;33(7):671-4.

14. Tleyjeh IM, Abdel-Latif A, Rahbi H, Scott CG, Bailey KR, Steckelberg JM, et al. A systematic review of population-based studies of infective endocarditis. Chest 2007;132(3):1025-35.

15. Tleyjeh IM, Steckelberg JM, Murad HS, Anavekar NS, Ghomrawi HM, Mirzoyev Z, et al. Temporal trends in infective endocarditis: a population-based study in Olmsted County, Minnesota.[see comment]. JAMA 2005;293(24):3022-8.

16. Seaworth BJ, Durack DT. Infective endocarditis in obstetric and gynecologic practice. Am J Obstet Gynecol 1986;154(1):180_8.

17. Campuzano K, Roque H, Bolnick A, Leo MV, Campbell WA. Bacterial endocarditis complicating pregnancy: case report and systematic review of the literature. Arch Gynecol Obstet 2003;268(4):251-5.

18. Shimoni Z, Ben David M, Niven MJ. Postpartum group B streptococcal tricuspid valve endocarditis. Isr Med Assoc J 2006;8(12):883-4.

19. Kulas T, Habek D. Infective puerperal endocarditis caused by Escherichia coli. J Perinat Med 2006;34(4):342-3. 
20. Ozkurt Z, Erkut B, Kadanali A, Ates A, Yekeler I. Nosocomial methicillin-resistant Staphylococcus aureus endocarditis with splenic abscess in a pregnant woman. Jpn J Infect Dis 2005;58(5):323-5.

21. Cunha BA, Hamid N, Kessler H, Parchuri S. Daptomycin cure after cefazolin treatment failure of Methicillin-sensitive Staphylococcus aureus (MSSA) tricuspid valve acute bacterial endocarditis from a peripherally inserted central catheter (PICC) line. Heart Lung 2005;34(6):442-7.

22. Aslam AF, Aslam AK, Thakur AC, Vasavada BC, Khan IA. Staphylococcus aureus infective endocarditis and septic pulmonary embolism after septic abortion. Int J Cardiol 2005;105(2):233-5.

23. Aoyagi S, Akasu K, Amako M, Yoshikawa K, Hori H. Infective endocarditis during pregnancy: report of a case. Ann Thorac Cardiovasc Surg 2005;11(1):51-4.

24. Fernando DMG, De Alwis LBL. Occlusion of a coronary ostium by an ingrowing endocardial vegetation: a case report. Med Sci Law 2004;44(2):179-81.

25. Montoya ME, Karnath BM, Ahmad M. Endocarditis during pregnancy. South Med J 2003;96(11):1156-7.
26. Crespo A, Retter AS, Lorber B. Group B streptococcal endocarditis in obstetric and gynecologic practice. Infect Dis Obstet Gynecol 2003;11(2):109-15.

27. Hughes LO, McFadyen IR, Raftery EB. Acute bacterial endocarditis on a normal aortic valve following vaginal delivery. Int J Cardiol 1988;18(2):261-2.

28. De Swiet M, de Louvois J, Hurley R. Letter: Failure to cephalosporins to prevent bacterial endocarditis during labour. Lancet 1975;2(7926):186.

29. Sexton DJ, Rockson SG, Hempling RE, Cathey CW. Pregnancy-associated group B streptococcal endocarditis: a report of two fatal cases. Obstet Gynecol 1985;66(3 Suppl):44S-7S.

30. Jemsek JG, Gentry LO, Greenberg SB. Malignant group B streptococcal endocarditis associated with saline-induced abortion. Chest 1979;76(6):695-7.

31. Kaufman D, Anaphylaxis TICSoS. Risk of anaphylaxis in a hospital population in relation to the use of various drugs: an international study. Pharmacoepidemiol Drug Saf 2003;12(3):195-202.

32. Hill JB, Sheffield JS, McIntire DD, Wendel GD Jr. Acute pyelonephritis in pregnancy. Obstet Gynecol 2005;105(1):18-23. 